\title{
Corrado Segre. A life dedicated to training young researchers
}

\section{Livia Giacardi}

Published online: 31 January 2014

(C) Centro P.RI.ST.EM, Università Commerciale Luigi Bocconi 2014 the Lettera Matematica International Edition celebrate that event:

Livia Giacardi, 'Corrado Segre. A Life Dedicated to Educating Young People in Mathematics';

Paola Gario, 'The birth of a School';

Ciro Ciliberto and Claudio Fontanari, 'Corrado Segre and the courses of higher geometry in Italy'.

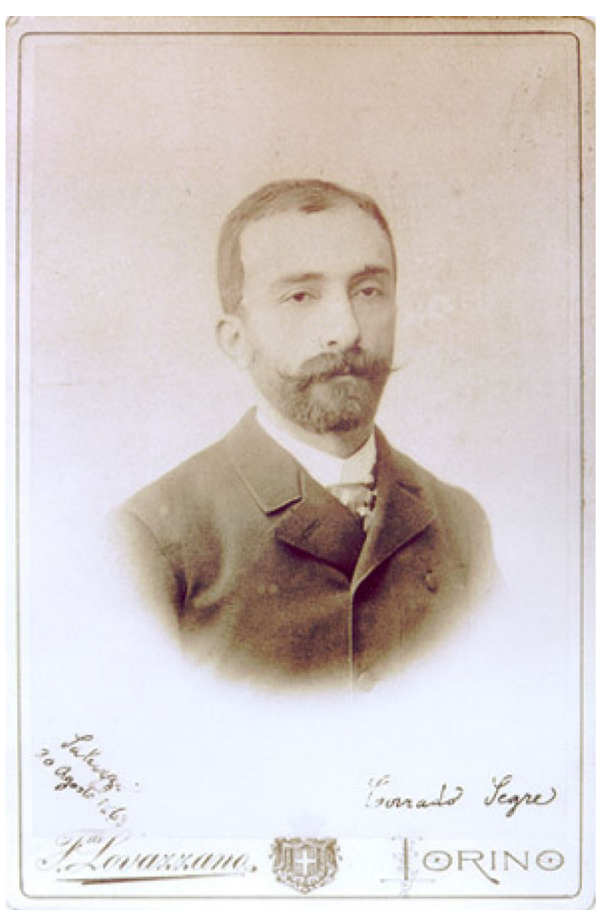

This group of papers is dedicated to a mathematician who played a fundamental role in the development of Italian algebraic geometry, created a famous School. As

\footnotetext{
Department of Mathematics, University of Turin,

Via Carlo Alberto, 10, 10123 Turin, Italy

e-mail: livia.giacardi@unito.it
}

Keywords Corrado Segre - Italian School of algebraic geometry · University of Turin

\section{Corrado Segre: 150 years later}

The 150th anniversary of the birth of Corrado Segre was celebrated on 20 August 2013. Three papers in this issue of 
these papers show, Segre's status as a maestro emerges clearly from his celebrated manuscript notebooks of lessons from 1888 to 1923 , in which the Piedmontese mathematician carefully recorded the contents of his courses, which varied from year to year.

\section{A life dedicated to educating young people in mathematics}

In 1904 Julian Coolidge wrote that Italian universities offered students who intended to pursue post-doctoral studies abroad all three of the requisites for a profitable period of study: well-stocked libraries, specialised courses, and the personal advisement of a professor [6: 12]. By way of example he cited the University of Torino, where he himself was doing post-doctoral studies in higher geometry with Corrado Segre. Coolidge's enthusiasm for Segre, who he defined as one of the greatest figures behind the 'geometric Risorgimento in Italy' [7: 352], is understandable: in the 2 decades at the turn of the 20th century, Segre had acquired the role of the head of the Italian School of geometric research, leading it to an internationally recognised position.

Born in Saluzzo, in the province of Cuneo, on 20 August 1863 to Abramo Segre and Estella De Benedetti, he completed his secondary studies at the Istituto tecnico Sommeiller in Torino, where his mathematics teacher was Giuseppe Bruno, who taught the upper biennium classes there, and was at the same time professor of projective and descriptive geometry at the university. Segre earned his diploma at 16 years old, and received a prize of 300 lire from the Chamber of Commerce for being first in his class. In 1879, against the wishes of his father (who wanted him to be an engineer), he enrolled in the degree course in mathematics at the University of Torino. He graduated with honours in 1883 with a dissertation entitled "Studio sulle quadriche in uno spazio lineare ad $n$ dimensioni ed applicazioni alla geometria della retta e specialmente delle sue serie quadratiche", written under the advisement of Enrico D'Ovidio. The dissertation was published that same year in two memoirs in the Atti of the Torino Academy of Sciences. ${ }^{1}$ His friend Guido Castelnuovo wrote:

Still today those who read ... the two strictly connected works remain surprised by the confidence and breadth of vision and [mathematical] means with which this young man, Corrado Segre, deals with this broad topic.

\footnotetext{
1 The thesis is published in two Memoirs: "Studio sulle quadriche in uno spazio lineare ad un numero qualunque di dimensioni" [24: III, 25-126] and "Sulla geometria della retta e delle sue serie quadratiche" [Segre 24: III, 127-217].
}

The dissertation appears due, not to a beginner, but to an experienced and skilled mathematician. ${ }^{2}$

Even at this early stage there emerged, along with Segre's passion for science, the firmness of character that distinguished the work of his entire lifetime. As his brother Arturo recalls:

The fourth year of university (1882-83) was especially difficult for him, a year that was exceedingly painful, during which my family went through economic collapse and the sad epilogue of my poor father. He composed his thesis in that terrible predicament, and took his degree in July 1883 with honours. $^{3}$

Winner of a competitive examination, in 1888 he was called to the professorship of higher geometry at the University of Torino, a chair that he held until his death. In 1893 he married Olga Michelli, with whom he had two daughters, Elena and Adriana (Fig. 1).

In addition to his courses at the university, he also taught for many years at the Scuola di Magistero, the teacher training school annexed to the Faculty of Sciences, becoming its director in 1916 (Fig. 2).

From 1909-10 to 1915-16 he was dean of the Faculty of Sciences, and from 1907 until his death he was director of the Biblioteca speciale di Matematica (today the Biblioteca 'Giuseppe Peano').

Segre's scientific activity went along several different lines, and in each of them he blazed new paths. ${ }^{4}$ His first works regarded above all the geometry of hyperspaces. With masterly recourse to the then recent algebraic results of Karl Weierstrass and Ferdinand Georg Frobenius, Segre was able to give a geometric and analytic formulation to the projective geometry of hyperspaces, taking it to the degree of development necessary for it to be used as an instrument for further research by the Italian school of geometry. In several brilliant memoirs, he also showed the usefulness of employing hyperspace to study properties of ordinary $\mathrm{S}_{3}$ space. A noteworthy example is the memoir entitled to 'Étude des différentes surfaces du $4^{\mathrm{e}}$ ordre à conique double ou cuspidale (générale ou décomposée)

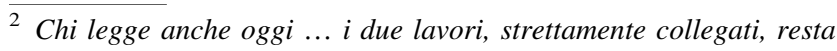
sorpreso della sicurezza e vastità di vedute e di mezzi con cui quel giovane, Corrado Segre, tratta l'ampio soggetto. La dissertazione sembra dovuta non già ad un principiante, ma ad un matematico provetto [4]

${ }^{3}$ Grave soprattutto fu per lui il $4^{\circ}$ anno d'università (1882-83), anno per noi dolorosissimo, nel quale la mia famiglia ebbe il crollo economico e l'epilogo triste di mio povero padre. Egli compose la tesi in quei terribili frangenti e prese la laurea nel luglio 1883 colla lode (Arturo Segre to Gino Fano, Torino, 29 June 1924, in [5: 11].

${ }^{4}$ For Segre's scientific work in general, see the prefaces by Severi, Terracini, Segre and Togliatti in [24]; see also [3, 12, 25].
} 


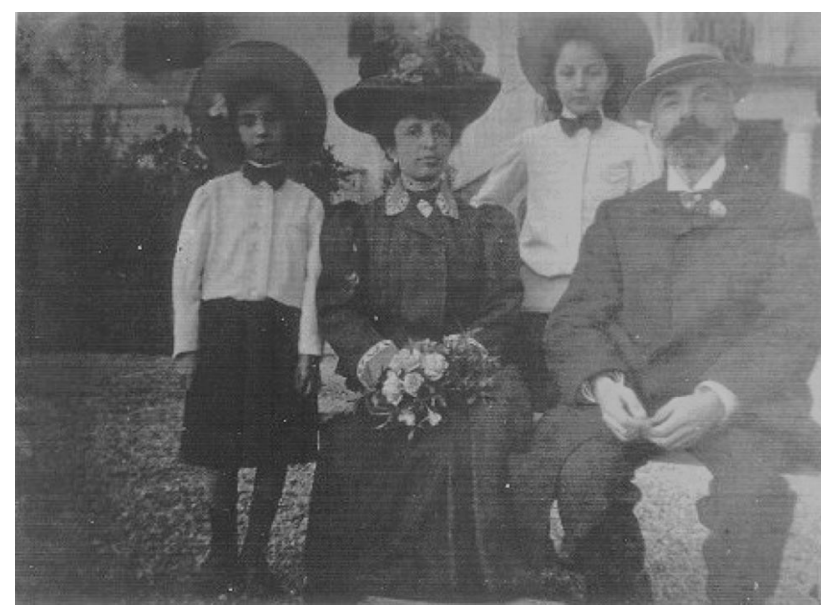

Fig. 1 Corrado Segre with his wife Olga and their daughters Elena and Adriana

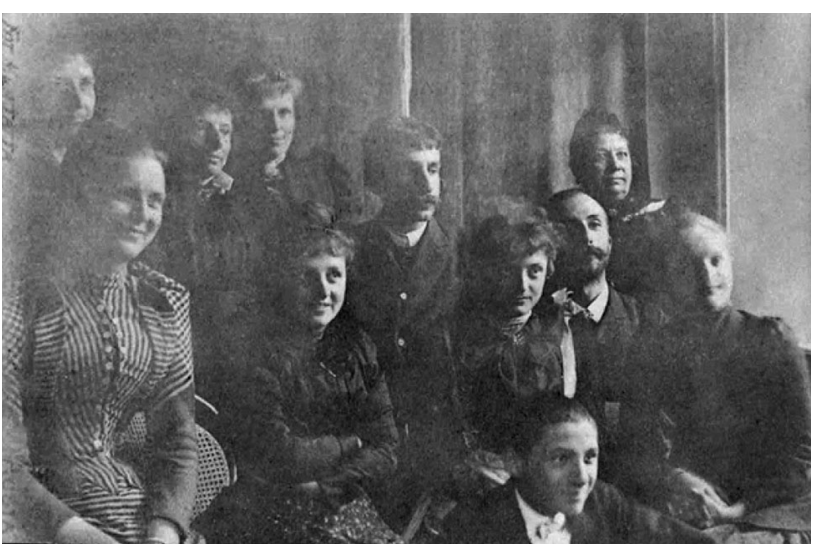

Fig. 2 Gino Loria and Corrado Segre (in the middle) with Luisa Pochintesta, Adelina Pochintesta, Sofia Rolandi-Meroni, Rachele Meroni, Pierino Meroni, Teresa Lorenzi-Galante, Sig. ${ }^{\text {a }}$ GuicciardiniVaj and Carla Marchesi-Taddei

considérées comme des projections de l'intersection de deux variétés quadratiques de l'espace à quatre dimensions' [17], in which he studies and classifies quartic surfaces with a double conic, considering them as projections of the intersection of two quadrics in fourdimensional space. The basic underlying idea of this work was also hit upon-independently-by Giuseppe Veronese, and constitutes the germ of the notion of normal variety. Already in the first works can be seen the distinguishing traits of Segre's scientific output, that is, their exquisitely 'geometric' character and the skilful interweaving of synthetic procedures and analytic methods. He wrote to Klein:

What you tell me about the effect on you made by the synthetic reasoning about the geometry of $n$ dimensions does not surprise me; it is only by living in $S_{n}$,

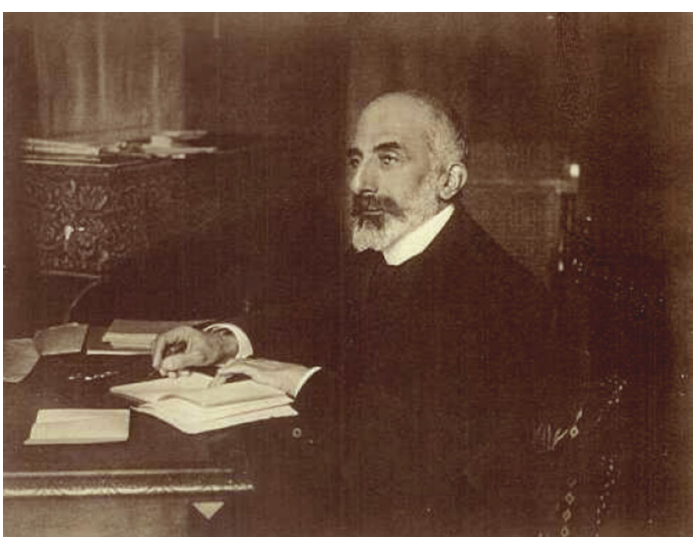

Fig. 3 Corrado Segre

by thinking about it always, that you become familiar with these arguments. ${ }^{5}$

Segre created a style, the Italian geometric style, with canons of method and canons of aesthetics: a geometric way of arguing, elegance and simplicity of treatment, enhancement of intuition without neglect for rigour. These questions of method and style, which brought with them a very precise vision of the teaching of advanced mathematics, are illustrated by Segre in the lengthy article entitled "Su alcuni indirizzi nelle investigazioni geometriche. Osservazioni dirette ai miei studenti" [18]. This article, which appeared in the first issue of the Rivista di matematica and was then translated into English [22], lies at the basis of the conflicts with Giuseppe Peano (Fig. 3), director of the Rivista and the other very important figure in the scientific world in Torino at the time. The clash between the two leaders of Schools was rekindled in 1910 when, with Segre as Dean of the Faculty of Sciences, Peano was removed from teaching higher analysis. ${ }^{6}$

Beginning in 1886 the works of Segre show a broadening of horizon under the influence on one hand of the new formulation of the German school of Alexander von Brill and Max Nöther and, on the other, of the ideas set out by Klein in his famous Erlangen Program, translated and published at Segre's initiative [8]. In his studies can therefore be discerned the progressive detachment from a restricted projective vision to arrive at the study of the properties that remain invariant under birational transformations. In the autumn of 1887, thanks to the good offices of Segre, Castelnuovo arrived in Torino as the assistant to D'Ovidio. This was the beginning of a fruitful scientific

\footnotetext{
${ }^{5}$ Ce que Vous me dites sur l'effet que Vous font les raisonnements synthétiques de géométrie à $n$ dimens. ne me surprend pas; c'est seulement en vivant dans $S_{n}$, en y pensant toujours, qu'on devient familier avec ces raisonnements (C. Segre to F. Klein, Torino 11 May 1887, in [13: 146]).

${ }^{6}$ For details, see $[1,10,16]$.
} 
collaboration between the two young men, one which was destined to continue even after Castelnuovo transferred to Rome in 1891, after having won a professorship there. The culminating work of this period is the important memoir entitled 'Introduzione alla geometria sopra un ente algebrico semplicemente infinito' [19], in which is also found the research carried out by Castelnuovo while in Torino, and which, as Francesco Severi wrote in his introduction to volume I of Segre's Opere, represents 'a milestone in the march of Italian geometry' [24: I, X]. In a short paper of 1891, Segre defined for the first time the product of linear spaces, today called 'Segre variety', a concept that 'had enormous repercussions for 20th-century geometry' [24: I, $\mathrm{XI}$. In another work entitled 'Intorno ad un carattere delle superficie e delle varietà superiori algebriche' [20] he introduced one of the most important relative invariants of an algebraic surface, today known as the 'Zeuthen-Segre invariant'.

Aware of the importance of establishing relationships with the European scientific community, in the summer of 1891 Segre undertook a trip to Germany, a country then at the vanguard of mathematical research, with the aim of visiting the principal institutes and libraries and making direct contact with those who had influenced his research. He visited Göttingen, Frankfurt, Nuremberg, Leipzig and Munich, and was able to meet Leopold Kronecker, Weierstrass, Max Nöther, Theodor Reye, Rudolf Sturm and Moritz Cantor, as well as Klein, whom until that time he had known only through letters. He wrote to Castelnuovo:

No one who has never been here can imagine what kind of man Klein is, and what kind of organisation he was able, with a skill that no one else could have, to impose on the mathematical studies in this university: it is something that has made an extraordinary impression on me. And I have already been most vividly impressed by the scientists that I have met on this journey! ${ }^{7}$

Another line of research inaugurated by Segre dates back to the first years of the 1890s, beginning with Karl von Staudt's theory of imaginary points, lines and planes in geometry. Thanks to Segre's initiative, Mario Pieri had published his translation of von Staudt's Geometrie der Lage [14], prefaced by a valuable biographical-bibliographical profile of the author written by Segre himself. Extending the German mathematician's field of research, Segre introduced a new kind of correspondence that he called 'antiprojectivity', developing a complete theory and paving the way for a new field of geometrical research, that of hyperalgebraic objects [21]. His results were later taken up and used by Elie Cartan.

\footnotetext{
${ }^{7}$ Segre to Castelnuovo, Göttingen, 30 June 1891, in [9].
}

By this time Segre had acquired notable fame both in Italy and abroad, so much so that he was invited to be vicepresident of the geometry section of the International Congress of Mathematicians in Zurich in 1897; his student Gino Fano gave one of the six lectures of the section. The following year, 1898, the Commission of the Premio Reale for mathematics offered by the Accademia dei Lincei in Rome awarded the prize equally to Segre and Vito Volterra, with a very favourable report praising the 'innovation and importance of the results' and underlining the elegance of the method that associates 'with rare ability geometric procedures with analytic procedures, grasping how intimately they are related' [15: 367]. From that moment on he was recognised as the leader of a School. At the turn of the century, Segre himself and his collaborators (Castelnuovo, Federigo Enriques, Fano, Luigi Berzolari and Gino Loria) were invited to collaborate on the Encyklopädie der Mathematischen Wissenschaften, to which they contributed no fewer than seven articles at that time. In 1904 Segre was invited to give a plenary lecture at the fourth International Congress of Mathematicians in Heidelberg, in which he provided a complete overview of the geometric research of the day and its relation to analysis, highlighting the lines of research that were most promising [23].

A third group of works defining yet another new area of research, projective differential geometry, dates to the years 1907-1913. The first paper dedicated expressly to the projective differential geometry of hyperspaces is dated 1907. It was, however, in the 1910 memoir entitled 'Preliminari di una teoria delle varietà luoghi di spazi' [24: II, 71-114] that Segre laid the bases for the systematic construction of that geometry, which would be given a great impetus by Guido Fubini.

The years between 1891 and 1912 were the most fruitful scientifically, and those which saw the birth of the Italian School of algebraic geometry which was to lead Torino and Italy to international recognition. ${ }^{8} \mathrm{~A}$ great number of young people wrote their theses on the most advanced research topics of the day under Segre's advisement: the most brilliant were Fano, Beppo Levi, Alberto Tanturri, Severi, Giovanni Giambelli, Alessandro Terracini and Eugenio Togliatti. There were many young people, Italians and foreigners, who, attracted by his fame, came to Torino to attend his lessons and do post-graduate work, such as, to name only the best known, Castelnuovo, Federico Amodeo, Enriques, Gaetano Scorza from Italy; the English husband and wife William H. Young and Grace Chisholm Young, the American Julian Coolidge and, some years later, also from the United States and Charles H. Sisam. In those years Segre presented no fewer than 107 works for

\footnotetext{
${ }^{8}$ On the formation of the Italian School of algebraic geometry in Torino, see [10].
} 
Fig. 4 Pages from Segre's manuscript notebook Introduzione alla geometria sugli enti algebrici semplicemente infiniti (1890-91). Image: [11]

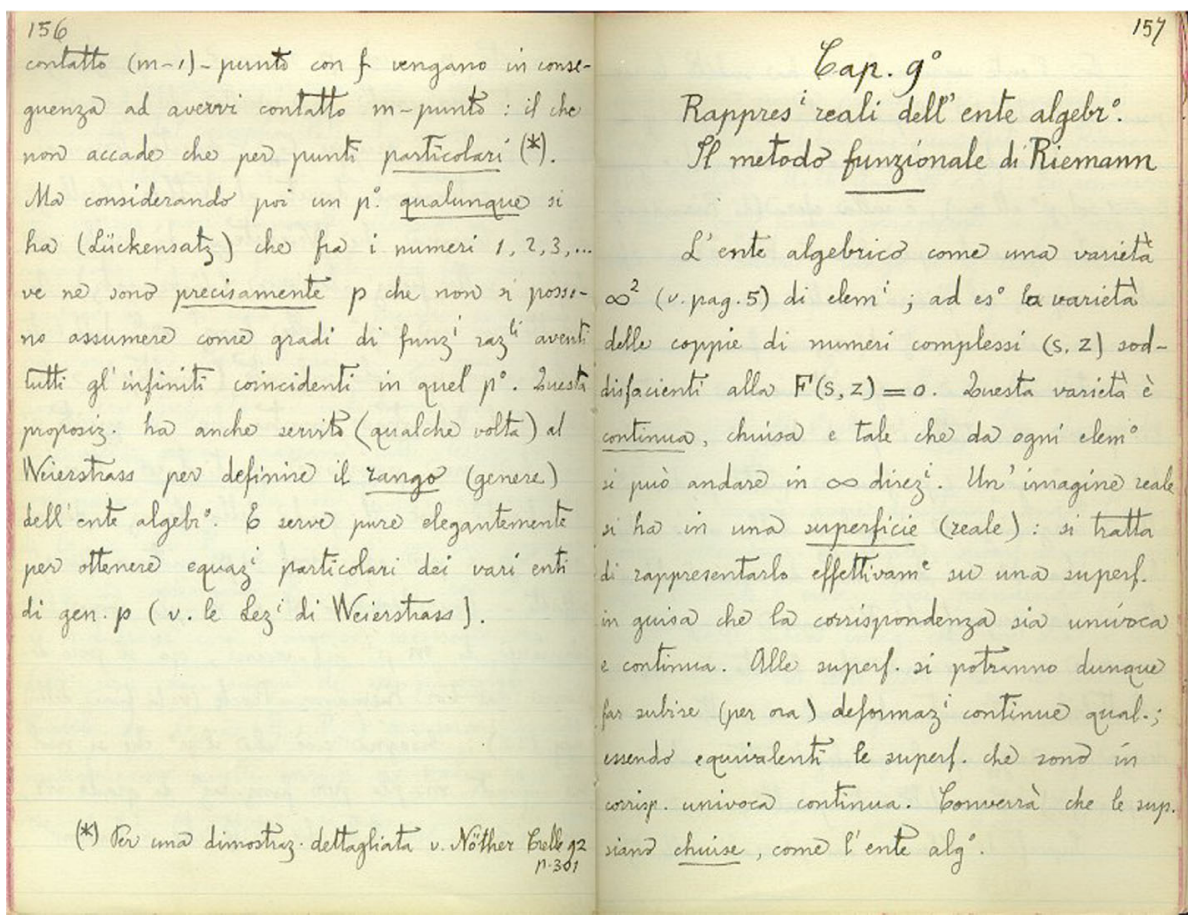

publication in the Atti of the Torino Academy of Sciences and wrote 34 reports on memoirs, the majority of which were by his students. 9

Still today Segre offers one of the history of mathematics' best models of the role of teacher and of School. When they had completed their training, Segre did not hesitate to put his students in contact with the most advanced international research and direct them towards topics most in keeping with their own inclinations, always encouraging to blaze new trails. It was his great intellectual generosity, combined with the high calibre of the students with whom he surrounded himself, that let the Italian School of algebraic geometry to reach an international level in the space of just a few years. The article "Su alcuni indirizzi ..." [18] cited earlier clearly shows how he used to set young people on the path to research: Segre invited them to deal only with important projects, and taught them to distinguish significant problems from those that were sterile and useless. He advised them to study, along with theories, their applications, and showed, through various examples, the importance of cultivating analysis and geometry together. He exhorted them not to be 'slaves to method', to not restrict their scientific activity too narrow a field, so that they could be able to consider 'things from a higher perspective', and suggested that they read the works of the great masters.

The best testimony to Segre's activities as a maestro and educator is given by the 40 manuscript notebooks in which,

\footnotetext{
${ }^{9}$ See [11]: Relazioni e Lavori presentati].
}

each summer, he carefully developed the topic of the course he was to teach that autumn (the topic changed from year to year) (Figs. 4, 5). ${ }^{10}$

They begin in 1888-89, the year in which Segre took over the professorship in higher geometry, and end in 1924, the year of his death. Written in a clear, minute hand, they are rich in bibliographic indications that show his great attention to sources, even the most recent. There are also considerations on methodology, brief historical notes and exercises, but above all there are suggestions for topics for study, or unsolved problems to be used with the aim of setting young people on the path to scientific research. It is no coincidence that the first works of Severi in enumerative geometry, or those of Giambelli and of Fano can trace their origins back to Segre's lessons. Even treatises show the influence of Segre's teaching: Enriques used them in compiling his Conferenze di Geometria (1894-95); in the preface to his book Introduzione alla geometria proiettiva degli iperspazi, Eugenio Bertini wrote that he had consulted 'the extensive manuscripts that Segre himself formulated annually for his courses' [2: 5]. Enriques and Oscar Chisini cited them in their Lezioni sulla teoria geometrica delle equazioni e delle funzioni algebriche (1915-1934), and Severi used them in his Trattato di

\footnotetext{
10 Today the notebooks are conserved in the 'Fondo Segre' in the Biblioteca matematica 'Giuseppe Peano' of the Università di Torino; they are reproduced with critical apparata in [11] and are being prepared for release on a forthcoming website.
} 
Fig. 5 Pages from Segre's manuscript notebook Introduzione alla geometria delle trasformaz. ${ }^{i}$ biraz. ${ }^{l i}$ del piano (1893-94). Image: [11]

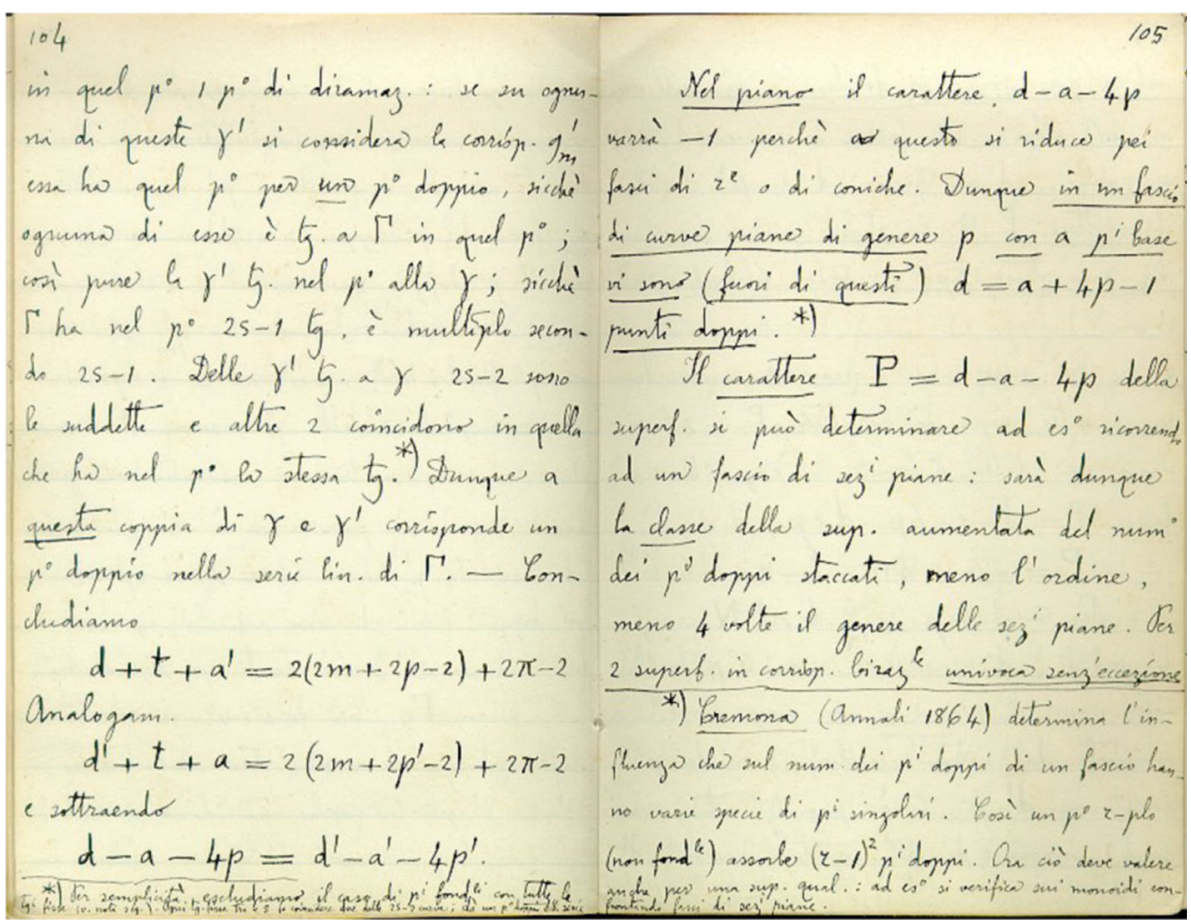

Geometria algebrica (1926), especially in the chapter on the geometry of an algebraic curve.

For Segre, therefore, 'School' indicates both a group of researchers who draw topics for investigation, methodology, approaches to research and a particular scientific style from the same master, as well as a place where talents are developed and contacts made, but also as a milieu in which a common vision of the transmission of knowledge is matured. Above all Segre taught his students that the object of scientific research is that of 'erecting the great edifice' of mathematics. As he put it, 'One result destined to remain in science is better than a thousand destined to die as soon as they are born' [18: 43].

His role of the leader of a School, as mentioned, had already been acknowledged as early as 1898. In 1923, Franz Meyer and Hans Mohrmann, in the introduction to the third volume of the celebrated Encyklopädie der mathematischen Wissenshaften, which sums up the state of international research in the field of geometry, underlined that fact that in just a few years at the end of the 19th century Italy had arrived to a führende Stellung, commanding position (III.I $\mathrm{I}_{1}$, p. VI) in the field of geometric research. Segre is surely one of the mathematicians who made the greatest contribution to that.

A national member of the Academy of Sciences in Torino from 1889, and of that of the Lincei from 1901, Segre was also a member of the most important scientific academies in Italy and abroad. Starting in 1905, for 20 years he was one of the directors of one of the most important scientific journals of the day, the Annali di
Matematica pura ed applicata, to which he contributed, together with his students, important articles, ever mindful of quality. A year before his death he wrote to Levi-Civita:

If you have someone else's papers to submit—do it: but with a certain degree of severity, as we do not live in times when we can be open-handed in printing; and on the other hand it matters to us for the Annals to maintain, or even elevate, their fame further. ${ }^{11}$

Corrado Segre died in Torino on 18 May 1924.

Translated from the Italian by Kim Williams

Acknowledgments All of the images are taken from [5].

\section{References}

1. Avellone, M., Brigaglia, A., Zappulla, C.: The Foundations of projective geometry in Italy from De Paolis to Pieri. Arch. Hist. Exact Sci. 56(5), 363-425 (2002)

2. Bertini, E.: Introduzione alla geometria proiettiva degli iperspazi. Enrico Spoerri, Pisa (1907)

3. Brigaglia, A., Ciliberto, C.: Italian algebraic geometry between the two world wars. Queen's Papers in Pure and Applied Mathematics, 100th edn. Queen's University, Kingston (1995)

\footnotetext{
${ }^{11}$ Se avete lavori di altri da presentare-scrive a Levi-Civita un anno prima di morire-fatelo: ma con una certa severità, ché non siamo in tempi in cui si possa esser larghi nello stampare; e d'altra parte c'importa che gli Annali mantengano, od anche elevino ulteriormente, la loro fama! Segre to Levi-Civita, Torino, 9 April 1923, Archivio Levi-Civita, Accademia Nazionale dei Lincei, Roma.
} 
4. Castelnuovo, G.: Commemorazione, Atti della R. Accademia dei Lincei, Rendiconti, s. 5 332, pp. 353-359 (1924)

5. Conte, A., Giacardi, L., Novaria, P.: Corrado Segre (1863-1924). A 150 anni dalla nascita, Catalogo delle Mostre documentarieTorino, Novembre 2013. Kim Williams Books, Torino (2013)

6. Coolidge, J.: The opportunities for mathematical study in Italy. Bull. Am. Math. Soc. 11, 9-17 (1904)

7. Coolidge, J.: Corrado Segre. Bull. Am. Math. Soc. 33, 352-357 (1927)

8. Fano, G.: Considerazioni comparative intorno a ricerche geometriche recenti. Annali di matematica pura ed applicata, s. 2 17, 307-343 (1890)

9. Gario, P.: (ed.). n.d. Lettere e Quaderni dell'Archivio di Guido Castelnuovo. http://archivi-matematici.lincei.it/Castelnuovo/ Lezioni_E_Quaderni/menu.htm (2013). Accessed 5 December 2013

10. Giacardi, L.: Corrado Segre maestro a Torino. La nascita della scuola italiana di geometria algebrica. Annali di storia delle università italiane 5, 139-163 (2001)

11. Giacardi, L. (ed.): I Quaderni di Corrado Segre (CD). Dipartimento di matematica, Università di Torino, Torino (2002)

12. Loria, G.: L'opera geometrica di Corrado Segre. Annali di Matematica pura ed applicata s.4(2), 1-21 (1924)

13. Luciano, E., Roero, C.S.: From Turin to Göttingen: dialogues and correspondence (1879-1923). Bollettino di Storia delle Scienze Matematiche 32, 9-232 (2012)

14. Pieri, M.: Geometria di posizione di G. C. C. v. Staudt. Bocca, Torino (1889)

15. Reale Accademia dei Lincei: Relazione sul concorso al premio reale per la Matematica, pel 1895. Atti della Reale Accademia dei Lincei, Rendiconti delle sedute solenni 1, 354-374 (1898)

16. Roero, C.S.: Maestri dell'Ateneo torinese dal Settecento al Novecento. In: Allio, R. (ed.) Giuseppe Peano geniale matematico, amorevole maestro. Pp. 115-144. Centro Studi di Storia dell'Università di Torino, Torino (2004)

17. Segre, C.: Étude des différentes surfaces du $4^{\mathrm{e}}$ ordre à conique double ou cuspidale (générale ou décomposée) considérées comme des projections de l'intersection de deux variétés quadratiques de l'espace à quatre dimensions. Mathematische Annalen 24, 3: 313-444. Rpt. in [Segre 1957-1963: III, 339-484] (1884)

18. Segre, C.: Su alcuni indirizzi nelle investigazioni geometriche. Osservazioni dirette ai miei studenti. Rivista di matematica 1, 42-66. Rpt. in [Segre 1957-1963: 4, 387-412] (1891)
19. Segre, C.: Introduzione alla geometria sopra un ente algebrico semplicemente infinito. Annali di Matematica pura ed applicata s.2, 22: 41-142. Rpt. in [Segre 1957-1963: I, 198-304] (1894)

20. Segre, C.: Intorno ad un carattere delle superficie e delle varietà superiori algebriche. Atti della Reale Accademia delle Scienze di Torino 31: 485-501. Rpt. in [Segre 1957-1963: I, 312-326] (1895-96)

21. Segre, C.: Un nuovo campo di ricerche geometriche. Atti della Reale Accademia delle Scienze di Torino 25 (1889-90): Nota I, 180-205; Nota II, 290-317; Nota III, 376-396; 26 (1890-91): Nota IV, 35-71. Rpt. in [Segre 1957-1963: II, 237-337] (1889-1891)

22. Segre, C.: On some tendencies in geometric investigations. Bull. Am. Math. Soc. 10, 442-468 (1904)

23. Segre, C.: La geometria d'oggidì e i suoi legami con l'analisi. Rendiconti Circolo matematico di Palermo 19: 81-93. Rpt. in [Segre 1957-1963: IV, 456-468] (1905)

24. Segre, C.: Opere, vol 4. Unione Matematica Italiana (ed.). Edizioni Cremonese Rome (1957-1963)

25. Terracini, A.: Corrado Segre (1863-1924). Jahresbericht der Deutschen Mathematiker-Vereinigung 35, 209-250 (1926)

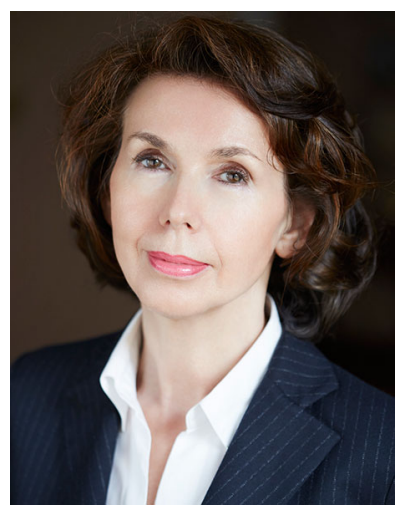

Livia Giacardi is a full professor of History of Mathematics at the University of Torino. Her research concerns the history of mathematics and history of mathematics education (19th and 20th centuries). She is the author of numerous essays, critical editions of unpublished documents, and books for both specialists and for a more general public. She is also editor of several CDs and websites devoted to the history of mathematics.

She collaborates with the International Group for Research on the History of Mathematics Education. She has been the Secretary of the Italian Society for the History of Mathematics from its founding in 2000 to 2008; she is currently a member of the Council. She is also a member of the Scientific Commission of the Italian Mathematical Union and is among the editors of journal $\mathrm{La}$ Matematica nella Società e nella Cultura. 